\title{
PERFIL EPIDEMIOLOGICO DOS PACIENTES COM TRAUMATISMO RAQUIMEDULAR NO BRASIL
}

\author{
Gerlane Justina da Silva ${ }^{3}$ \\ Gisele Calado 4 \\ Wagner Pereira da Silva ${ }^{5}$
}

\begin{abstract}
RESUMO
O traumatismo raquimedular (TRM) refere-se a uma condição caracterizada por lesão da medula espinhal ocasionada por trauma, seja ela permanente ou temporária, podendo lesionar a parte ósseo-ligamentar, medular, discal ou radicular. Este estudo teve como objetivo identificar o perfil epidemiológico do traumatismo raquimedular no Brasil. Tratou-se de uma revisão integrativa da literatura de estudos envolvendo publicações científicas sobre traumatismo, epidemiologia, medula espinhal, coluna vertebral e fratura. A Pesquisa foi realizada de Julho a Novembro de 2016, com artigos científicos publicados de 2011 a 2016, conforme o enfoque temático, cenários das pesquisas, metodologia aplicada e período de publicação. Após a pesquisa nas bases de dados foram achados 860 artigos, depois de aplicar os critérios preestabelecidos, restaram 25 e após a leitura integral, foram utilizados 19. Os artigos incluídos, nesta revisão, foram descritos conforme: o nome do periódico, título do artigo, autor (es), cenário da pesquisa, metodologia aplicada, ano da publicação, objetivos, etiologia, sexo e cidade e idade. Conclui-se que no Brasil há um grande número de pessoas lesionadas, esse evento causa um grande impacto socioeconômico no país, por se tratar de jovens em idade produtiva.
\end{abstract}

Palavras-chave: traumatismo, epidemiologia, medula espinal, coluna vertebral e fratura.

\footnotetext{
${ }^{3}$ Bacharel em Enfermagem.

${ }^{4}$ Enfermeira residente em nefrologia - IMIP.

${ }^{5}$ Major do Corpo de Bombeiros Militar de Pernambuco, Mestre em Ciências da Saúde - FCM/ICB UPE.
} 


\title{
THE EPIDEMIOLOGICAL PROFILE OF PATIENTS WITH RAQUIMEDULAR TRAUMATISM IN BRAZIL
}

\begin{abstract}
Spinal cord trauma (MRT) refers to a condition characterized by injury to the spinal cord caused by trauma, whether permanent or temporary, and may injure the osseoligamentous, medullary, discal or radicular part. This study aimed to identify the epidemiological profile of spinal cord injury in Brazil. It was an integrative review of the literature of studies involving scientific publications on trauma, epidemiology, spinal cord, spine and fracture. The research was carried out from July to November 2016, with scientific articles published from 2011 to 2016, according to the thematic focus, research scenarios, applied methodology and publication period. After the search in the databases, 860 articles were found, after applying the pre-established criteria, 25 were left and after full reading, 19 were used. The articles included in this review were described as: the name of the journal, title of the article, Author (s), research scenario, and applied methodology, year of publication, objectives, etiology, sex and city and age. It is concluded that in Brazil there are a large number of injured people, this event causes a great socioeconomic impact in the country, because they are young people of productive age.
\end{abstract}

Keywords: trauma, epidemiology, spinal cord, spine, fracture.

\section{Artigo recebido em 30/06/17 e Aceito em 16/10/17.}

\section{INTRODUÇÃO}

O termo traumatismo raquimedular (TRM) refere-se a uma condição caracterizada por lesão da medula espinhal ocasionada por trauma, seja ela permanente ou temporária, podendo ter lesão ósseo-ligamentar, medular, discal ou radicular. É uma das causas frequentes de morbi-mortalidade mundial e causa alterações nas atividades do sistema intestinal, urinário, respiratório, circulatório, reprodutor, dentre outros (BERNARDI, 2014; VIUDES, 2015). 
O número de pessoas lesionadas multiplicou-se nos últimos anos e esse episódio é constantemente atribuído aos fatores externos, como a violência urbana e os acidentes de trânsito, sendo considerados como causas principais, os acidentes automobilísticos, ferimento por arma de fogo (FAF), arma branca, quedas e mergulho em águas rasas. Essas causas estão relacionadas a certas práticas habituais, como a impulsividade, exposição ao risco de violência, abuso do álcool, imprudência e imperícia no trânsito (SANTOS 2012; SANTIAGO, 2012).

De acordo com a estimativa americana avaliada em 2004, podemos observar o grande número de casos novos, aproximadamente 10 mil casos por ano, ou seja, de 30 a 40 casos/por milhão de habitantes, presumindo-se que 250.000 pessoas vitimadas, residem no país, com idade média de 20 a 24 anos, e 65\% estão abaixo de 35 anos, evidenciando a causa principal: os acidentes de trânsito (50\%) e quedas (20\%). No Brasil ocorre cerca de 6.000 a 8.000 mil casos por ano, computando-se um gasto médio de 9 bilhões por ano, no entanto, não é notificada, são feitas apenas estimativas de incidência e prevalência, ressaltando que não há dados recente (MORAIS, 2013; VIUDES, 2015).

Estudos realizados no Hospital Sarah Kubitschek no primeiro semestre de 2015 evidenciaram que $22,37 \%$ das internações foram ocasionadas por causas externas. Os acidentes de trânsito foram a primeira causa de internação por esse trauma, com $48,9 \%$ dos casos, as agressões, incluindo: arma de fogo, arma branca e agressão física, constituem a segunda causa externa de internação com $24,8 \%$ dos casos. Por fim, aparecem ainda, como causas externas nessa pesquisa, as quedas $(15,2 \%)$, os acidentes de mergulho $(4,7 \%)$, e os impactos por objetos pesados $(1,7 \%)$, entre outras (4,8\%) (BRASIL, 2015)

A lesão irreversível da coluna é um evento agudo e inesperado que altera radicalmente a vida do indivíduo, ficando limitado a executar suas 
atividades diárias, necessitando da cooperação de outras pessoas, o que acarretará numa mudança de comportamento, demonstrando sentimentos de agressividade, isolamento social, medo, tristeza e revolta, e, além disso, tendo sua autoestima afetada, interferindo na sua qualidade de vida, pois necessitará do apoio dos familiares, amigos e dos profissionais de saúde para se adaptar a nova condição (CREONCIO, 2012).

Além disso, o aumento da expectativa de vida desses indivíduos fez com que aumentassem os olhares para a reabilitação, prevenção e não menos importante a qualidade de vida e a independência funcional. Porém, para se habituar a nova realidade, viver de maneira diferente e superando obstáculos, é preciso participar de programas de reabilitação, exigindo abstenção de horas de lazer do cuidador e tendo que optar por hábitos e atividades convenientes a nova condição (VENTURINI, 2007).

A escolha desse tema foi devido ao aumento da violência urbana e os acidentes de trânsitos, causas principais desse trauma, que vêm acarretando um gasto pecuniário adicional para o Sistema Único de Saúde (SUS) e também para a Previdência Social, salientando que são pacientes jovens em idade produtiva. É importante destacar que há poucos trabalhos sobre essa temática, o que torna o estudo importante para possível colaboração de propostas de medidas preventivas. Assim sendo, este estudo teve como objetivo identificar o perfil epidemiológico do trauma raquimedular no Brasil.

\section{MÉTODOS}

Tratou-se de uma revisão integrativa da literatura envolvendo publicações científicas sobre o perfil epidemiológico do trauma raquimedular no Brasil.

Para elaboração da presente revisão foram preconizadas as seguintes etapas: 1- identificação do tema e seleção da hipótese 2- estabelecimento de critérios para inclusão e exclusão de estudos; 3- definição das informações a 
serem extraídas dos estudos selecionados; 4- avaliação dos estudos incluídos na revisão integrativa; 5- interpretação de resultados; 6- apresentação da revisão/síntese do conhecimento.

$\mathrm{Na}$ coleta de dados foi realizada a busca de artigos científicos nos bancos de dados da Bireme e Scielo- Scientific Electronic Library Online (http://www.scielo.org), através das fontes Lilacs-Literatura Latino-americana e do Caribe em Ciências da Saúde (http://www.bireme.br/bvs), Medline- Medical literature Analysisand Retrieval System Online, BDEnf - Base de Dados em Enfermagem. Essa busca utilizou as terminologias cadastradas nos Descritores em Ciências da Saúde - DCS, criados pela Biblioteca Virtual em Saúde - BVS que permite o uso da terminologia comum em Português, Inglês e Espanhol. Os descritores utilizados na busca foram: traumatismo, epidemiologia, medula espinhal, coluna vertebral, fratura e lesões da medula espinhal. Foi utilizado como ferramenta de auxílio, o operador Booleano "AND", para o cruzamento dos descritores.

A Pesquisa foi realizada de Julho a Novembro de 2016, com artigos científicos publicados de 2011 a 2016, conforme o enfoque temático, cenários das pesquisas, metodologia aplicada e período de publicação. Como critérios de inclusão foram selecionados artigos completos e originais, publicados em Português e/o Inglês, que apresentavam especificidade com o tema e a problemática do estudo; que continha as palavras-chave selecionadas; aqueles publicados no período 2011 a 2016 e que foram desenvolvidos com dados coletados no Brasil. Foram excluídos artigos de revisão bibliográfica e publicações fora do período supracitado, incompletos ou produzidos com dados de outros países.

\section{RESULTADOS E DISCUSSÃO}

Ao realizar a pesquisa nas bases de dados foram encontrados 860 artigos, depois de aplicados os critérios preestabelecidos, restaram 25 e após a 
Revista Científica do Corpo de Bombeiros Militar de Pernambuco

Seção 1 - Artigos Técnico Científicos

Artigo publicado no Vol.03 N07 - Edição de JUL a DEZ 2017 - ISSN 2359-4829

Versão on-line disponível em: http://www.revistaflammae.com.

leitura integral foram utilizados 19 artigos. Os artigos incluídos, nesta revisão, estão abaixo descritos conforme: o nome do periódico, título do artigo, autor (es) (quadro 1); cenário da pesquisa, metodologia aplicada, ano da publicação (quadro 2);objetivos, etiologia, sexo, cidade/Estado e idade (quadro 3).

Quadro 1. Resumo dos estudos pesquisados envolvendo periódico, título e autor.

\begin{tabular}{|c|c|c|}
\hline PERIÓDICO & TÍTULO & AUTOR \\
\hline $\begin{array}{l}\text { Jornal Brasileiro } \quad \text { de } \\
\text { Neurocirurgia }\end{array}$ & $\begin{array}{l}\text { Epidemiologia do } \\
\text { Raquimedular }\end{array}$ & Pereira, C.U. et al. \\
\hline $\begin{array}{ll}\text { (EFDEPORTES) } & \text { Revista } \\
\text { Digital. Buenos Aires } & \end{array}$ & $\begin{array}{l}\text { Perfil epidemiológico do } \\
\text { traumatismo raquimedular em } \\
\text { pacientes atendidos em um hospital } \\
\text { da rede publica de Manaus, AM }\end{array}$ & Reis, J.A.P. et al. \\
\hline Revista Coluna/Columna & $\begin{array}{l}\text { Casuísta de trauma raquimedular } \\
\text { tratado em hospital terciário de } \\
\text { Palmas, Brasil }\end{array}$ & Castro, D.L. et al. \\
\hline Revista Coluna/Columna & $\begin{array}{l}\text { Analise de pacientes com trauma } \\
\text { raquimedular associado a } \\
\text { traumatismo cranioencefálico }\end{array}$ & Neto, J.S.M. et al. \\
\hline $\begin{array}{l}\text { VXI Seminário } \\
\text { interinstitucional de ensino, } \\
\text { pesquisa e extensão }\end{array}$ & $\begin{array}{l}\text { Perfil clinico e epidemiológico dos } \\
\text { pacientes com lesão medular } \\
\text { atendidos no centro de atendimento } \\
\text { a deficiência (CAD) }\end{array}$ & Bühler, M.A. et al. \\
\hline Revista Coluna/Columna & $\begin{array}{l}\text { Caracterização clinica de das } \\
\text { situações de fratura da coluna } \\
\text { vertebral no município de Ribeirão } \\
\text { Preto, propostas para um programa } \\
\text { de prevenção do trauma } \\
\text { raquimedular }\end{array}$ & $\begin{array}{l}\text { Vasconcelos, } \\
\text { E.C.L.M. et al. }\end{array}$ \\
\hline Rev. Col. Bras. Cir. & $\begin{array}{l}\text { Avaliação epidemiológica dos } \\
\text { pacientes vitima de traumatismo } \\
\text { raquimedular }\end{array}$ & Brito, L.M.O et al. \\
\hline ArqBrasNeurocir & $\begin{array}{l}\text { Perfil epidemiológico dos pacientes } \\
\text { com fratura na coluna cervical } \\
\text { tratados cirurgicamente no serviço } \\
\text { de neurocirurgia do hospital de } \\
\text { base do Distrito Federal }\end{array}$ & Tavares, C.B. et al. \\
\hline Revista Coluna/Columna & $\begin{array}{l}\text { Estudo clinico epidemiológico das } \\
\text { fraturas da coluna vertebral }\end{array}$ & Fernandes, RB et al. \\
\hline $\begin{array}{l}\text { Revista } \\
\text { (online) }\end{array}$ & $\begin{array}{l}\text { Perfil clinico e epidemiológico de } \\
\text { pacientes com traumatismo } \\
\text { raquimedular }\end{array}$ & Santos, R.A. et al. \\
\hline Revista Coluna/Columna & $\begin{array}{l}\text { Perfil epidemiológico dos pacientes } \\
\text { com traumatismo raquimedular } \\
\text { atendidos em hospital terciário }\end{array}$ & Morais, D.F. et al. \\
\hline $\begin{array}{l}\text { Fisioterapia da Pesquisa } \\
\text { (online) }\end{array}$ & $\begin{array}{l}\text { Estudo do perfil do trauma } \\
\text { raquimedular em Porto Alegre }\end{array}$ & Frison, V.B. et al. \\
\hline ArqBrasNeurocir & Perfil epidemiológico dos pacientes & Tavares, C.B et al. \\
\hline
\end{tabular}


Revista Científica do Corpo de Bombeiros Militar de Pernambuco

Seção 1 - Artigos Técnico Científicos

Artigo publicado no Vol.03 Nº7 - Edição de JUL a DEZ 2017 - ISSN 2359-4829

Versão on-line disponível em: http://www.revistaflammae.com.

\begin{tabular}{|c|c|c|}
\hline & $\begin{array}{l}\text { com fraturas torácicas e lombares } \\
\text { tratados cirurgicamente no serviço } \\
\text { de neurologia do hospital de Base } \\
\text { do Distrito Federal ( Brasilia-Brasil) }\end{array}$ & \\
\hline $\begin{array}{l}\text { Jornal Brasileiro de } \\
\text { neurocirurgia }\end{array}$ & $\begin{array}{l}\text { Aspectos clínico-epidemiológicos } \\
\text { do trauma raquimedular no hospital } \\
\text { de urgência de Petrolina }\end{array}$ & $\begin{array}{l}\text { Creôncio, S.C.E et } \\
\text { al. }\end{array}$ \\
\hline $\begin{array}{l}\text { Arquivos Brasileiros de ciência } \\
\text { da saúde }\end{array}$ & $\begin{array}{l}\text { Aspectos sociodemograficos e } \\
\text { clínicos de homens com lesão } \\
\text { medular traumática em um centro } \\
\text { urbano do nordeste brasileiro }\end{array}$ & $\begin{array}{l}\text { Santiago, L.M.M. et } \\
\text { al. }\end{array}$ \\
\hline $\begin{array}{ll}\text { (EFDEPORTES) } & \text { Revista } \\
\text { digital. Buenos Aires } & \end{array}$ & 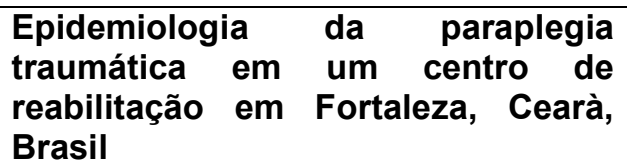 & Silva, G.A. et al. \\
\hline Revista Coluna/Columna & $\begin{array}{l}\text { Perfil epidemiológico da cirurgia de } \\
\text { trauma raquimedular em hospital de } \\
\text { referência no interior do Brasil }\end{array}$ & Bernardi, DM. \\
\hline ArqNeuropsiquiatr & $\begin{array}{l}\text { Complicações clínicas em pacientes } \\
\text { com trauma raquimedular cervical } \\
\text { grave: estudo prospectivo de dez } \\
\text { anos }\end{array}$ & Santos, E.A.S. et al. \\
\hline ArqBrasNeurocir & $\begin{array}{l}\text { Avaliação do perfil epidemiológico } \\
\text { do lesado medular traumático de } \\
\text { um serviço de coluna do } \\
\text { Estado do Espírito Santo }\end{array}$ & Scopel, G. et al. \\
\hline
\end{tabular}

As revistas apresentadas no quadro 1, mostram que as áreas de interesse no assunto são variadas, pois abrangem profissionais de diversas áreas, entre elas estão fisioterapia $(15,7 \%)$, medicina- ortopedia, neurocirurgia e neuropsiquiatria - $(68,4 \%)$, educação física $(10,5 \%)$ e revistas de interesse comum na saúde - Ciências da Saúde (5,2\%).Esse resultado corrobora com BRITO, 2011 e FRISON, 2013, eles relatam que a equipe de reabilitação que cuida destes pacientes é multiprofissional, composta por médicos de diversas especialidades e enfermeiros, assistentes sociais, fonoaudiólogos, fisioterapeutas, psicólogos dentre outros, o que confirma a complexidade desse tipo de trauma. 
Revista Científica do Corpo de Bombeiros Militar de Pernambuco Seção 1 - Artigos Técnico Científicos

Artigo publicado no Vol.03 No07 - Edição de JUL a DEZ 2017 - ISSN 2359-4829

Versão on-line disponivel em: http://www.revistaflammae.com.

\section{PROFISSÕES QUE PUBLICARAM SOBRE O TEMA}

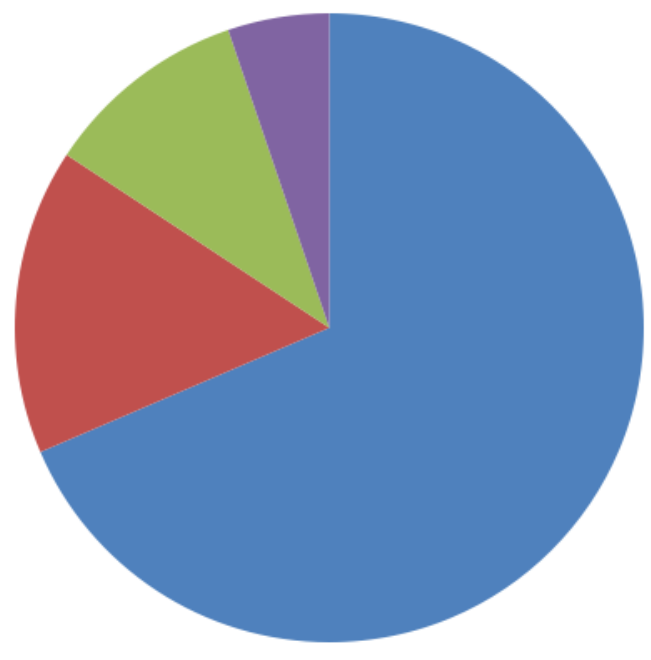

MEDICINA

- FISIOTERAPIA

" EDUCAÇÃO FÍSICA

- CIÊNCIAS DA SAÚDE

Quadro 2. Resumo dos estudos pesquisados envolvendo cenários, metodologia e ano.

\begin{tabular}{|c|c|c|}
\hline CENÁRIOS & METODOLOGIA & ANO \\
\hline $\begin{array}{l}\text { Hospital de Urgência de Sergipe } \\
\text { (HUSE) }\end{array}$ & $\begin{array}{l}\text { Estudo prospectivo, transversal e } \\
\text { descritivo }\end{array}$ & 2011 \\
\hline Hospital Público de Manaus- AM & $\begin{array}{l}\text { Estudo prospectivo, quanti- } \\
\text { qualitativa }\end{array}$ & 2013 \\
\hline $\begin{array}{l}\text { Hospital Geral Público de } \\
\text { Palmas (HGPP)- TO }\end{array}$ & $\begin{array}{l}\text { Estudo prospectivo, quanti- } \\
\text { qualitativa }\end{array}$ & 2015 \\
\hline $\begin{array}{l}\text { Hospital de Base de São José } \\
\text { do Rio Preto, SP. }\end{array}$ & $\begin{array}{l}\text { Estudo prospectivo, transversal e } \\
\text { descritivo }\end{array}$ & 2014 \\
\hline $\begin{array}{l}\text { Centro de Atendimento a } \\
\text { Deficiência (CAD)-RS }\end{array}$ & Estudo retrospectivo descritivo & 2011 \\
\hline $\begin{array}{l}\text { Hospital da Clinicas da } \\
\text { Faculdade de Medicina de } \\
\text { Ribeirão Preto da Universidade } \\
\text { de São Paulo (HCFMRP-USP) }\end{array}$ & Estudo retrospectivo descritivo & 2011 \\
\hline $\begin{array}{l}\text { Serviço de Neurocirurgia do } \\
\text { HUPD, São Luiz/MA }\end{array}$ & Estudo transversal retrospectivo & 2011 \\
\hline $\begin{array}{l}\text { Serviço de neurologia do } \\
\text { Hospital de Base do Distrito } \\
\text { Federal em Brasília }\end{array}$ & $\begin{array}{l}\text { Estudo retrospectivo, quanti- } \\
\text { qualitativa }\end{array}$ & 2016 \\
\hline Hospital Geral da Bahia & Estudo retrospectivo descritivo & 2012 \\
\hline $\begin{array}{l}\text { Hospital Público referencia em } \\
\text { traumas, Salvador- BA }\end{array}$ & Estudo transversal descritivo & 2013 \\
\hline $\begin{array}{l}\text { Hospital de Base de São José } \\
\text { do Rio Preto, (SP) }\end{array}$ & $\begin{array}{lll}\text { Estudo descritivo do } & \text { tipo, } \\
\text { transversal prospectivo } & \\
\end{array}$ & 2013 \\
\hline Hospital Cristo Redentor (HCR) & Estudo transversal e retrospectivo & 2013 \\
\hline
\end{tabular}




\section{Revista FLAMMAE}

Revista Científica do Corpo de Bombeiros Militar de Pernambuco Seção 1 - Artigos Técnico Científicos

Artigo publicado no Vol.03 Nº7 - Edição de JUL a DEZ 2017 - ISSN 2359-4829

Versão on-line disponivel em: http://www.revistaflammae.com.

\begin{tabular}{|l|l|l|}
\hline $\begin{array}{l}\text { e do Hospital Pronto Socorro } \\
\text { (HPS), Porto Alegre - RS }\end{array}$ & 2013 \\
\hline $\begin{array}{l}\text { Serviço de neurologia do } \\
\text { Hospital de Base do Distrito } \\
\text { Federal em Brasília }\end{array}$ & $\begin{array}{l}\text { Estudo retrospectivo, quanti- } \\
\text { qualitativa }\end{array}$ & 2012 \\
\hline $\begin{array}{l}\text { Hospital de Urgência e Traumas } \\
\text { (HUT), Petrolina - PE }\end{array}$ & Estudo retrospectivo descritivo & 2012 \\
\hline $\begin{array}{l}\text { Centros de atendimentos } \\
\text { Fisioterápicos em Natal-RN }\end{array}$ & Pesquisa quanti-qualitativa & 2012 \\
\hline $\begin{array}{l}\text { Centro de Reabilitação em } \\
\text { Fortaleza- CE }\end{array}$ & $\begin{array}{l}\text { Estudo exploratório descritivo, } \\
\text { transversal e prospectivo, } \\
\text { quantitativo quano }\end{array}$ & 2012 \\
\hline $\begin{array}{l}\text { Hospital Regional do Noroeste, } \\
\text { Paranavaí - PR }\end{array}$ & Pesquisa quanti-qualitativa & 2011 \\
\hline $\begin{array}{l}\text { Hospitais de Urgências em São } \\
\text { Paulo }\end{array}$ & Pesquisa quanti-qualitativa & 2015 \\
\hline $\begin{array}{l}\text { Hospitais particulares e públicos } \\
\text { do estado do Espírito Santo }\end{array}$ & Estudo transversal e descritivo & \\
\hline
\end{tabular}

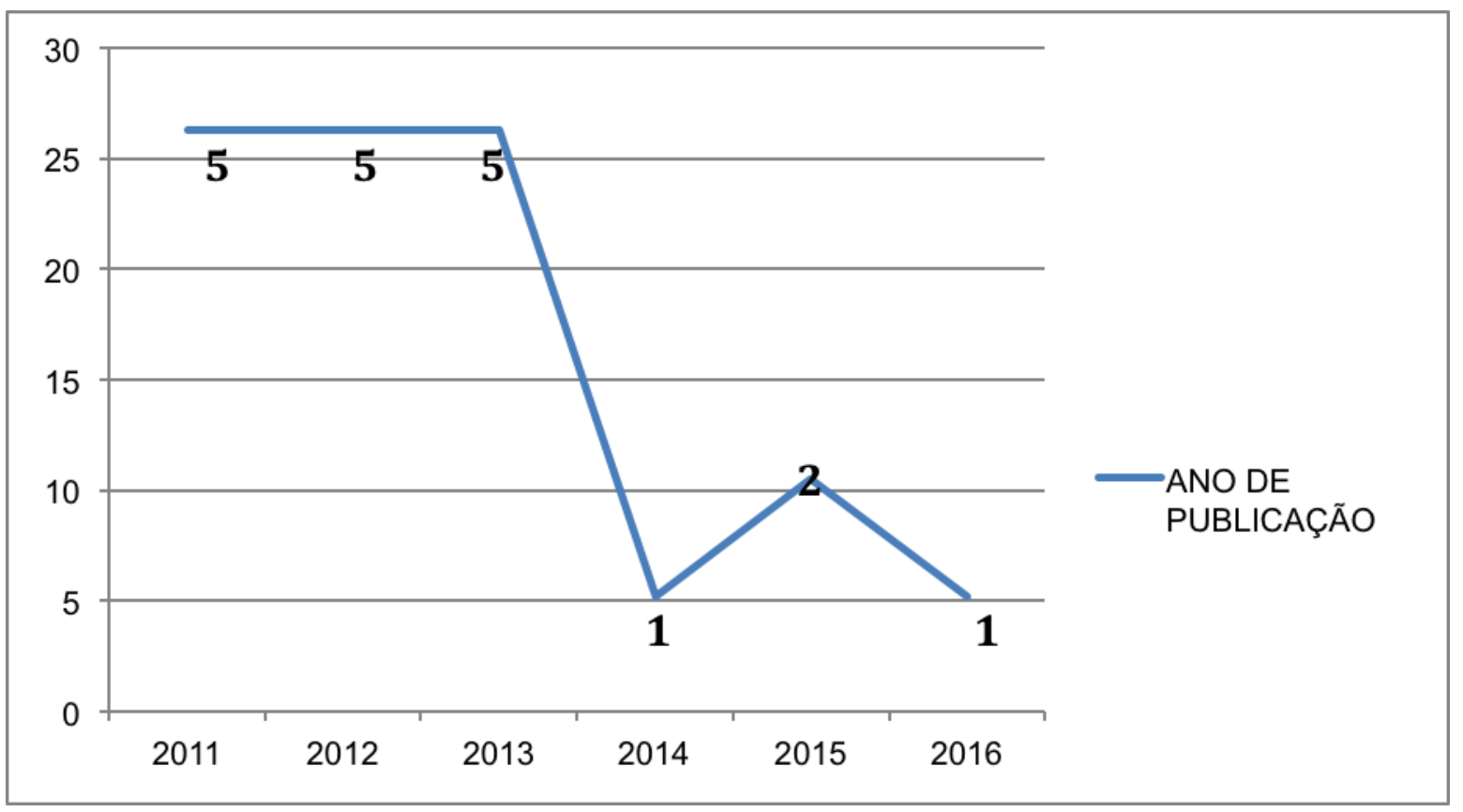

As pesquisas foram realizadas em hospitais gerais, hospitais de urgências, hospitais referência em traumas, centros de reabilitação e fisioterápico. Isso demonstra que a diversidade de interesse no TRM ocorre não apenas no atendimento de emergência, mas também na reabilitação. 
Revista Científica do Corpo de Bombeiros Militar de Pernambuco Seção 1 - Artigos Técnico Científicos

Artigo publicado no Vol.03 N07 - Edição de JUL a DEZ 2017 - ISSN 2359-4829

Versão on-line disponível em: http://www.revistaflammae.com.

Nos 19 (dezenove) estudos foram realizadas pesquisas de campo, no entanto apenas $03(15,78 \%)$ foram através de dados primários sendo os demais $16(84,22 \%)$ desenvolvidos com dados secundários.

Quanto ao ano de publicação, em 2011, 2012 e 2013 tiveram a mesma quantidade de artigos publicados, ou seja, $05(26,31 \%)$ para cada ano, sendo que no ano de 2013, as publicações foram distribuídas uma em cada região do país (Norte, Nordeste, Centro-Oeste, Sudeste e Sul). Em 2014 e 2016, houve uma diminuição, apenas 01(5,26\%) em cada ano e em 2015 foram publicados $02(10,52 \%)$.

No Nordeste o maior número de publicações se deu em 2012, de 05 estudos publicados, 04 foram dessa região. Em 2014, 2015 e 2016 houve apenas 04 publicações. Reis et al, 2013 e Creôncio, 2012, afirmaram que o número maior dos pacientes em seu estudo é oriundo do interior, onde geralmente não tem centros especializados para este tipo de lesão. Scopel et al, 2015, divergem quanto a procedência e assegura que $50 \%$ são proveniente da região metropolitana.

Reis et al, 2013, também afirmou que os dados nacionais sobre a epidemiologia do TRM são insuficientes e ressalta que é preciso mais estudos sobre esse agravo, para desenvolver medidas preventivas.

Quadro 3. Resumo dos estudos pesquisados envolvendo objetivos, etiologia, sexo, cidade/Estado e idade.

\begin{tabular}{|c|c|c|c|c|}
\hline OBJETIVOS & ETIOLOGIA & SEXO & $\begin{array}{c}\text { CIDADE/EST } \\
\text { ADO }\end{array}$ & IDADE \\
\hline $\begin{array}{c}\text { Avaliação epidemiológica de } 120 \text { casos } \\
\text { de traumatismo raquimedular. }\end{array}$ & $\begin{array}{c}\text { Acidentes } \\
\text { automobilísticos }\end{array}$ & Masculino & \begin{tabular}{|c|} 
Aracaju/ \\
Sergipe \\
\end{tabular} & 21 a 30 \\
\hline $\begin{array}{c}\text { Estudar os aspectos epidemiológicos do } \\
\text { Traumatismo Raquimedular (TRM) em } \\
\text { pacientes internados no período de } \\
\text { outubro e novembro de } 2010, \text { no } \\
\text { município de Manaus-AM }\end{array}$ & $\begin{array}{l}\text { Acidentes } \\
\text { automobilísticos } \\
\text { e Quedas de } \\
\text { árvores }\end{array}$ & Masculino & $\begin{array}{l}\text { Manaus/ } \\
\text { Amapá }\end{array}$ & 40 a 49 \\
\hline $\begin{array}{c}\text { Traçar o perfil clínico-epidemiológico do } \\
\text { trauma raquimedular (TRM), em } \\
\text { Palmas-TO }\end{array}$ & $\begin{array}{c}\text { Acidentes } \\
\text { automobilísticos }\end{array}$ & Masculino & $\begin{array}{l}\text { Palmas/ } \\
\text { Tocantins }\end{array}$ & 41 a 50 \\
\hline $\begin{array}{c}\text { Caracterizar vítimas de trauma } \\
\text { raquimedular (TRM) associado a } \\
\text { traumatismo cranioencefálico (TCE) e } \\
\text { fatores de risco }\end{array}$ & $\begin{array}{c}\text { Acidentes } \\
\text { automobilísticos }\end{array}$ & Masculino & $\begin{array}{l}\text { São José do } \\
\text { Rio Preto/ } \\
\text { São Paulo }\end{array}$ & 21 a 30 \\
\hline
\end{tabular}


Revista FLAMMAE

Revista Científica do Corpo de Bombeiros Militar de Pernambuco

Seção 1 - Artigos Técnico Científicos

Artigo publicado no Vol.03 Nº7 - Edição de JUL a DEZ 2017 - ISSN 2359-4829

Versão on-line disponível em: http://www.revistaflammae.com.

\begin{tabular}{|c|c|c|c|c|}
\hline $\begin{array}{c}\text { Elaborar um perfil clínico e } \\
\text { epidemiológico dos pacientes com lesão } \\
\text { medular, atendidos no centro de } \\
\text { atendimento a deficiência (CAD). }\end{array}$ & $\begin{array}{c}\text { Acidentes } \\
\text { automobilísticos }\end{array}$ & Masculino & $\mid \begin{array}{c}\text { Passo Fundo/ } \\
\text { Rio Grande } \\
\text { do Sul }\end{array}$ & 18 a 35 \\
\hline $\begin{array}{l}\text { Caracterização clinica e avaliação das } \\
\text { situações relacionada ao trauma } \\
\text { raquimedular, no Hospital das Clinicas } \\
\text { da Faculdade de Medicina de Ribeirão } \\
\text { Preto durante } 2007 \text { e } 2008 \text {. }\end{array}$ & $\begin{array}{c}\text { Acidentes } \\
\text { motociclistico }\end{array}$ & Masculino & $\begin{array}{l}\text { Ribeirão } \\
\text { Preto/São } \\
\text { Paulo }\end{array}$ & 21 a 30 \\
\hline $\begin{array}{l}\text { Fazer avaliação epidemiológica de } 87 \\
\text { pacientes vítimas de traumatismo da } \\
\text { medula espinhal, internados no hospital } \\
\text { universitário da UFMA entre Janeiro de } \\
2008 \text { e Junho de } 2009 \text {. }\end{array}$ & Quedas gerais & Masculino & $\begin{array}{l}\text { São Luizl } \\
\text { Maranhão }\end{array}$ & 21 a 30 \\
\hline $\begin{array}{l}\text { Apresentamos o perfil epidemiológico de } \\
48 \text { pacientes com fratura traumática da } \\
\text { coluna cervical tratados cirurgicamente } \\
\text { no serviço de neurocirurgia do Hospital } \\
\text { de Base do Distrito Federal. }\end{array}$ & $\begin{array}{c}\text { Acidentes } \\
\text { automobilísticos }\end{array}$ & Masculino & $\begin{array}{l}\text { Brasília/ } \\
\text { Distrito } \\
\text { Federal }\end{array}$ & 20 a 40 \\
\hline $\begin{array}{c}\text { Realizar um levantamento } \\
\text { epidemiológico das fraturas da coluna } \\
\text { vertebral }\end{array}$ & Quedas gerais & Masculino & $\begin{array}{l}\text { Salvador/ } \\
\text { Bahia }\end{array}$ & 20 a 29 \\
\hline $\begin{array}{c}\text { Identificar o perfil clínico e } \\
\text { epidemiológico dos pacientes adultos } \\
\text { com traumatismo raquimedular (TRM) } \\
\text { em um centro de referência em traumas } \\
\text { na Bahia. }\end{array}$ & Quedas gerais & Masculino & $\begin{array}{l}\text { Salvador/ } \\
\text { Bahia }\end{array}$ & 31 a 40 \\
\hline $\begin{array}{c}\text { Avaliar o perfil epidemiológico de } \\
\text { pacientes com traumatismo } \\
\text { raquimedular atendidos em hospital } \\
\text { terciário. }\end{array}$ & $\begin{array}{c}\text { Acidentes } \\
\text { automobilísticos }\end{array}$ & Masculino & $\begin{array}{l}\text { São José do } \\
\text { Rio Preto }\end{array}$ & 21 a 30 \\
\hline $\begin{array}{l}\text { Traçar o perfil da população que sofreu } \\
\text { trauma raquimedular(TRM) e foi } \\
\text { internada em hospitais de pronto } \\
\text { atendimento de Porto Alegre/RS. }\end{array}$ & Quedas gerais & Masculino & $\begin{array}{l}\text { Porto } \\
\text { Alegre/Rio } \\
\text { Grande do } \\
\text { Sul }\end{array}$ & 40 a 49 \\
\hline $\begin{array}{l}\text { Caracterização clinica e avaliação das } \\
\text { situações relacionada ao trauma } \\
\text { raquimedular, no Hospital das Clinicas } \\
\text { da Faculdade de Medicina de Ribeirão } \\
\text { Preto durante } 2007 \text { e } 2008 \text {. }\end{array}$ & $\begin{array}{c}\text { Acidentes } \\
\text { motociclistico }\end{array}$ & Masculino & $\begin{array}{l}\text { Ribeirão } \\
\text { Preto/São } \\
\text { Paulo }\end{array}$ & 21 a 30 \\
\hline $\begin{array}{l}\text { Fazer avaliação epidemiológica de } 87 \\
\text { pacientes vítimas de traumatismo da } \\
\text { medula espinhal, internados no hospital } \\
\text { universitário da UFMA entre Janeiro de } \\
2008 \text { e Junho de } 2009 \text {. }\end{array}$ & Quedas gerais & Masculino & $\begin{array}{l}\text { São Luizl } \\
\text { Maranhão }\end{array}$ & 21 a 30 \\
\hline $\begin{array}{l}\text { Apresentamos o perfil epidemiológico de } \\
48 \text { pacientes com fratura traumática da } \\
\text { coluna cervical tratados cirurgicamente } \\
\text { no serviço de neurocirurgia do Hospital } \\
\text { de Base do Distrito Federal. }\end{array}$ & $\begin{array}{c}\text { Acidentes } \\
\text { automobilísticos }\end{array}$ & Masculino & $\begin{array}{l}\text { Brasília/ } \\
\text { Distrito } \\
\text { Federal }\end{array}$ & 20 a 40 \\
\hline $\begin{array}{c}\text { Realizar um levantamento } \\
\text { epidemiológico das fraturas da coluna } \\
\text { vertebral }\end{array}$ & Quedas gerais & Masculino & $\begin{array}{l}\text { Salvador/ } \\
\text { Bahia }\end{array}$ & 20 a 29 \\
\hline Identificar o perfil clínico e & Quedas gerais & Masculino & Salvador/ & 31 a 40 \\
\hline
\end{tabular}


Revista FLAMMAE

Revista Científica do Corpo de Bombeiros Militar de Pernambuco

Seção 1 - Artigos Técnico Científicos

Artigo publicado no Vol.03 Nº7 - Edição de JUL a DEZ 2017 - ISSN 2359-4829

Versão on-line disponível em: http://www.revistaflammae.com.

\begin{tabular}{|c|c|c|c|c|}
\hline $\begin{array}{c}\text { epidemiológico dos pacientes adultos } \\
\text { com traumatismo raquimedular (TRM) } \\
\text { em um centro de referência em traumas } \\
\text { na Bahia. }\end{array}$ & & & Bahia & \\
\hline $\begin{array}{l}\text { Avaliar o perfil epidemiológico de } \\
\text { pacientes com traumatismo } \\
\text { raquimedular atendidos em hospital } \\
\text { terciário. }\end{array}$ & $\begin{array}{l}\text { Acidentes } \\
\text { automobilísticos }\end{array}$ & Masculino & $\begin{array}{l}\text { São José do } \\
\text { Rio Preto }\end{array}$ & 21 a 30 \\
\hline $\begin{array}{l}\text { Traçar o perfil da população que sofreu } \\
\text { trauma raquimedular(TRM) e foi } \\
\text { internada em hospitais de pronto } \\
\text { atendimento de Porto Alegre/RS. }\end{array}$ & Quedas gerais & Masculino & $\begin{array}{l}\text { Porto } \\
\text { Alegre/Rio } \\
\text { Grande do } \\
\text { Sul }\end{array}$ & 40 a 49 \\
\hline $\begin{array}{c}\text { Apresentar o perfil epidemiológico e os } \\
\text { fatores de risco para déficit neurológico } \\
\text { de } 52 \text { pacientes com fratura traumática } \\
\text { da coluna torácica e lombar tratados } \\
\text { cirurgicamente no Serviço de } \\
\text { Neurocirurgia do Hospital de Base do } \\
\text { Distrito Federal. }\end{array}$ & $\begin{array}{l}\text { Acidentes } \\
\text { automobilísticos }\end{array}$ & Masculino & $\begin{array}{l}\text { Brasília/ } \\
\text { Distrito } \\
\text { Federal }\end{array}$ & 20 a 40 \\
\hline $\begin{array}{c}\text { Avaliar epidemiologicamente os casos } \\
\text { de TRM ocorridos no Vale do São } \\
\text { Francisco. }\end{array}$ & $\begin{array}{l}\text { Acidentes } \\
\text { motociclístico }\end{array}$ & Masculino & $\begin{array}{l}\text { Petrolina/ } \\
\text { Pernambuco }\end{array}$ & 21 a 30 \\
\hline $\begin{array}{l}\text { Caracterizar, de acordo com aspectos } \\
\text { sociodemográficos e clínicos, uma } \\
\text { amostra de homens com lesão medular, } \\
\text { residentes na cidade de Natal (RN), } \\
\text { Brasil. }\end{array}$ & $\begin{array}{l}\text { Ferimento por } \\
\text { arma de fogo } \\
\text { (FAF) }\end{array}$ & Masculino & $\begin{array}{l}\text { Natal/Rio } \\
\text { Grande do } \\
\text { Norte }\end{array}$ & 21 a 35 \\
\hline $\begin{array}{l}\text { Investigar o perfil epidemiológico de } \\
\text { pessoas com paraplegia traumática } \\
\text { participantes de um programa de } \\
\text { reabilitação,segundo as variáveis: idade, } \\
\text { sexo,tempo e etiologia, nível de } \\
\text { classificação pelo critério ASIA } \\
\text { (American spinalinjuryassociation), } \\
\text { tempo de hospitalização e escolaridade. }\end{array}$ & $\begin{array}{l}\text { Ferimento por } \\
\text { arma de fogo } \\
\text { (FAF) }\end{array}$ & Masculino & $\begin{array}{l}\text { Fortaleza/ } \\
\text { Ceará }\end{array}$ & 21 a 30 \\
\hline $\begin{array}{l}\text { Analisar o perfil epidemiológico desses } \\
\text { pacientes tratados cirurgicamente em } \\
\text { um hospital de referência do interior. }\end{array}$ & $\begin{array}{l}\text { Acidentes } \\
\text { motociclisticos }\end{array}$ & Masculino & $\begin{array}{l}\text { Paranavaí/ } \\
\text { Paraná }\end{array}$ & 21 a 30 \\
\hline $\begin{array}{l}\text { Identificar complicações decorrentes do } \\
\text { trauma raquimedular cervical grave. }\end{array}$ & $\begin{array}{l}\text { Acidentes } \\
\text { automobilísticos }\end{array}$ & Masculino & $\begin{array}{c}\text { São } \\
\text { Paulo/São } \\
\text { Paulo }\end{array}$ & 20 a 40 \\
\hline $\begin{array}{l}\text { Analisar o perfil epidemiológico dos } \\
\text { pacientes com traumatismo } \\
\text { raquimedular(TRM) submetidos a } \\
\text { procedimentos cirúrgicos no estado do } \\
\text { Espírito Santo. }\end{array}$ & $\begin{array}{l}\text { Acidentes } \\
\text { automobilísticos }\end{array}$ & Masculino & $\begin{array}{l}\text { Espírito } \\
\text { Santo }\end{array}$ & 20 a 24 \\
\hline
\end{tabular}

O Brasil é dividido geograficamente em cinco regiões: Norte, Nordeste, Centro-Oeste, Sudeste e Sul. Foi identificado pelo menos, um estudo de trauma raquimedular em cada região. Na Região Norte foi encontrado 02 (10.52\%) estudos, sendo 01 (um) em Palmas - TO e 01 (um) em Manaus-AM. 
No Nordeste, foram encontrados 07 (36,84\%) estudos: 01 (um) em São Luiz MA, 01 (um) em Petrolina-PE, 01 (um) em Natal-RN, 01 (um) em Fortaleza-CE, 02 (dois) em Salvador-BA e 01 (um) em Aracaju - SE. No centro Oeste, apenas 02 (dois) em Brasília-DF (10,52\%). No Sudeste, foram encontradas pesquisas nas seguintes cidades: 01 (um) em Ribeirão Preto-SP, 02 (dois) em São José do Rio Preto-SP, 01 (um) em São Paulo-SP e 01 (um) no Espírito Santo (Estado) totalizando 05 (26,31\%). E no Sul foram encontrados 03 (15,78\%), na cidade de Paranavaí-PR, Passo Fundo - RS e Porto Alegre - RS.

As causas do TRM em todas as pesquisas foram: acidentes automobilísticos $(52,5 \%)$, quedas em geral $(21,1 \%)$, acidentes motociclísticos $(15,7 \%)$, FAF $(10,5 \%)$ e quedas de árvores $(5,2 \%)$. Dentre as causas, os acidentes automobilísticos prevaleceram seguidos de quedas em geral, divergindo do estudo de Bernardi, 2014 e Creôncio, 2012. Que mostraram como etiologia prevalente, os acidentes motociclísticos (BERNARDI, 2014; CREÔNCIO, 2012).

As causas se diferenciam de acordo com as regiões e Estado. $\mathrm{Na}$ região Norte, 02 (dois) estudos mostram que as principais causas do TRM foram acidentes de trânsito e quedas de árvores. Reis et al, 2013 relataram que maioria dos pacientes eram provenientes do interior, isso justifica as quedas das árvores, pois os indivíduos rotineiramente se expõem aos riscos, devido há uma prática habitual da população de extrair frutas subindo nas árvores.

$\mathrm{Na}$ região Nordeste, nos 07 (sete) estudos avaliados, houve discrepância quanto à causa. $\mathrm{Na}$ cidade de Fortaleza e Natal, predominou o ferimento por arma de fogo. Santiago, 2012 e Silva, 2012 relataram crescimento humano e urbano desordenado dessas capitais, ocasionando vários problemas socioeconômicos, entre eles o aumento da violência urbana e a insegurança.

Junior et al, 2011 corroboram com os autores acima e relatam em sua pesquisa que o principal motivo do disparo por arma de fogo foi assalto e 
acontecia frequentemente aos fins de semana, tendo a região da coluna torácica mais atingida, justificando por conter o maior número de vértebras e essa circunstância do TRM geralmente causa perda total do nível neurológico, elevando a gravidade da lesão.

Em Aracaju e Petrolina, destacaram-se os acidentes de trânsito ocasionados por carro e moto. Nas cidades que se destacam por acidente de trânsito, Creôncio, 2012 diz que em Petrolina a moto é um dos meios de transporte mais utilizado, no entanto, as pessoas não obedecem às leis de trânsito, principalmente, quanto ao uso de equipamentos de proteção, como capacete. Vasconcelos, 2011 afirma que além de não usar o capacete e o cinto de segurança, a maioria dos pacientes lesionados havia ingerido bebida alcoólica.

Outro estudo no estado da Bahia e em São Luiz destacou-se as quedas gerais como as maiores causas do TRM. Brito, 2011 relata que as quedas de laje se sobressaem quando se trata de quedas, justificando que a população mais atingida são os mais pobres, pois o crescimento vertical, materializado pela construção de sobrados nas favelas, onde utilizam a laje como quintal para fazer festas e comemorações.

No Centro-Oeste 02 (duas) pesquisas realizadas em Brasília prevaleceram os acidentes automobilísticos. No Sudeste brasileiro foram encontrados 05 (cinco) estudos nessa região, em todas as pesquisas foram prevalentes os acidentes automobilísticos e motociclísticos. Uma pesquisa realizada em um centro de reabilitação em 2015 corrobora com esses estudos, predominando os acidentes de trânsito e afirma o crescente aumento da frota nacional de motocicletas e o aumento do envolvimento dessa categoria em acidentes de trânsito, fizeram com que a maioria $(52,0 \%)$ dos pacientes internados na Rede SARAH, 2015 fossem de usuários (condutores ou passageiros) de motocicletas e automóveis 
No Sul em 03 (três) estudos, dois apontaram os acidentes de trânsito e 01 (um) as quedas gerais. As quedas ocorreram em um estudo em Porto Alegre, e chama a atenção para os acidentes de trabalho, Frison, 2013 relatou que há uma necessidade de melhoria na segurança do trabalho, onde ocorrem muitos acidentes e também educação no trânsito. Nesse estudo algumas vitimas relataram que necessitam de atenção, cautela e prudência, quanto ao uso dos equipamentos de proteção individual e as leis de trânsito

Em relação aos acidentes de trânsito, Reis et al, 2013 e Vasconcelos, 2011 afirmaram que algumas vitimas que não obedeciam as leis de trânsito, outras queixaram-se por mal sinalização das vias públicas, também foi exposto a falta de uso do cinto de segurança e do capacete, além da insensatez e falta de atenção com esses fatores que propiciaram o acidente. De acordo com esses relatos, fica nítida a necessidade de investimentos na manutenção e ampliação em campanhas educativas no trânsito, sobretudo quanto ao uso dos equipamentos de segurança.

Venturini, 2007 afirma que os lesionados na década de 80 pertenciam a um melhor nível socioeconômico, tendo a média salarial por família acima de 15 (quinze) salários mínimos. Atualmente o perfil socioeconômico dos indivíduos acometidos pelo TRM é diferente, e acredita-se que essa mudança se deve ao fato de que as camadas menos favorecidas da sociedade aumentaram seu poder de compra, incluindo carros e motos através do financiamento

Nos estudos houve um predomínio do sexo masculino e a faixa etária dominante foram os jovens de 21 a 30 anos. Atribui-se essa prevalência ao fato de se tratar de jovens, que se expõem mais aos riscos, se comportando de maneira desafiadora e imprudente (BERNARDI, 2014; SANTIAGO, 2012; MORAIS, 2013; CREÔNCIO, 2012; NETO, 2014; BUHLER, 2014; VASCONCELOS, 2011). 
Em contrapartida os autores Pereira, 2011 e Brito, 2011 confirmaram que apesar do predomínio ser maior em homens, o número de mulheres que apresentaram TRM vem aumentando, isso devido a inserção da mulher no mercado de trabalho, como construção civil, por exemplo, justificando as quedas, mas também devido a autonomia da mulher no trânsito, pois, elas passaram a conduzir carros e motos, se expondo ao risco.

Em 09 (nove) dos estudos mostraram que a coluna cervical foi mais atingida. Segundo Creôncio, 2012 em sua pesquisa houve um elevado percentual de fraturas na cervical e ele justifica que os acidentes motociclísticos são responsáveis por esse segmento afetado, sendo mais comuns os acidentes com moto.

A região torácica ficou em segundo lugar com 06 (seis) dos estudos. Lourenço, 2008 afirma que o segmento da coluna torácica é o mais acometido quando a causa é FAF, alegando que a região torácica tem maior chance de ser atingida por conter um número maior de vértebras.

Esse agravo é um significativo problema de saúde pública, observando que os cidadãos terão que suspender suas atividades profissionais, necessitando do auxílio da Previdência Social, causando um grande impacto na economia do País (CREÔCIO, 2012).

Mendes, 2007 relata que o beneficio por invalidez ainda é a forma de aquisição de renda predominante entre os vitimados. Essa aposentadoria pode representar pra algumas pessoas uma desonra, tendo dificuldade de retornar ao mercado de trabalho, julgando-se incapaz. A vontade de voltar a trabalhar, se depara com o medo de ser demitido, pois a volta ao trabalho regularizado requer suspensão do benefício.

\section{CONSIDERAÇÕES FINAIS}

$\mathrm{O}$ trauma raquimedular foi mais frequente no sexo masculino, de modo mais específico, em indivíduos adultos jovens na faixa etária entre 21 e 30 
anos. A etiologia da lesão mais frequente foram os acidentes de trânsito e as quedas, a região cervical foi a mais acometida. No Brasil há um grande número de pessoas lesionadas, esse evento causa um grande impacto socioeconômico no país, por se tratar de jovens em idade produtiva, que deixaram de contribuir para a previdência social e passaram a depender do auxílio do Instituto Nacional do Seguro Social (INSS). Além da previdência social, também ocasiona um custo ao sistema único de saúde (SUS), na prevenção, no atendimento de emergência e na recuperação.

Para os acidentes com veículos automotores, sugere-se ter maior empenho na fiscalização das regras de trânsito, bem como, insistir na conscientização dos condutores, através de educação continuada e demais politicas publicas acerca do tema.

Nesse sentido, se demonstra a importância deste trabalho para o setor de saúde pública, incluindo-se a área de enfermagem, podendo subsidiar a implementação de novas medidas de enfretamento dessa problemática. $O$ enfermeiro como profissional da saúde que mantém contato diário no acompanhamento desta população específica, em qualquer que seja o nível de complexidade, deve estar inserido nesta discussão para aprofundamento na temática, contribuindo com o planejamento de ações para o cuidado destes pacientes e assim, favorecer sua recuperação.

Devido à carência de estudos sobre o tema sugere-se a realização de novos estudos instituidores de políticas de prevenção e controle dos acidentes de trânsito sendo os principais geradores do trauma raquimedular.

\section{REFERÊNCIAS}

BENARD, D.M. Perfil epidemiológico da cirurgia de trauma raquimedular em hospital de referência no interior do Brasil. Coluna/columna. 2014; 13(2):136138. 
Brasil. Rede Sarah de Hospitais de Reabilitação, 2015 disponível em: http://www.sarah.br/programas-educacionais/estudos-epidemiologicos; [acessado em 2016 Mai 25].

BRITO L.M.O; CHEIN M.B.C; MARINHO S.C; DUARTE T.B. Avaliação epidemiológica dos pacientes vítima de traumatismo raquimedular. Rev. Col. Bras. Cir.; 38(5): 304-309, 2011.

BUHLER, M.A; LUCATELLI. V.; AMARAL, R.B.; ROCKENBACH, C.W.F; Perfil clinico e epidemiológico dos pacientes com lesão medular atendidos no centro de atendimento a deficiência (CAD). XVI SEMINÁRIO interinstitucional de ensino, pesquisa e extensão, IX MOSTRA de extensão. .www.unicruz.edu.br/seminário, 2014.

CASTRO, D.L. et al. Casuística de trauma raquimedular tratado em hospital terciário de Palmas, Brasil. Coluna/columna. 2015, 14(3): 214-7.

CREÔNCIO, S.C.E; MOURA, J.C; RANGEL, B.L.R. Aspectos Clínicoepidemiológicos do trauma raquimedular no hospital de urgências e traumas Petrolina-PE J Bras Neurocirurg 23 (3): 211-216, 2012.

FERNANDES, R.B. et al. Estudo clínico epidemiológico das fraturas da coluna vertebral. Coluna/columna. 2012; 11(3): 230-3.

FRISON, V.B; TEIXEIRA, G.O; OLIVEIRA, T.F; RESENDE, T.L; NETTO, C.A. Estudo do perfil do trauma raquimedular em Porto Alegre. Fisioter Pesq. 2013; 20(2): 165-171.

JUNIOR, F.A.R. et al. Traumatismo raquimedular por ferimento de projétil de arma de fogo: avaliação epidemiológica. Coluna/columna. 2011; 10(4): 290-2.

LOURENÇO, L.J.O.; ALVES, E.M.; ANDRADE, A.F. Lesões raquimedulares associado ao traumatismo crânio-encefálico grave ou moderado. Coluna/Columna 2008; 7(2): 143-5.

MENDES, L.G.G. Subjetividade e lesão medular: vida que escapa a paralisia. Dissertação (Mestrado) - Universidade Católica de Minas Gerais, Belo Horizonte, 2007.p. 108-9.

MORAIS, D.F. et al. Perfil epidemiológico dos pacientes com traumatismo raquimedular atendidos em hospital terciário. Coluna/columna.2013; 12(2) 149-52. 
NETO, J.S.M.; TOGNOLA, W.A.; SPOTTI, A.R.; MORAIS, D.F. Análise de pacientes com trauma raquimedular associado traumatismo cranioencefálico. Coluna/columna. 2014; 13(4): 302-5.

PEREIRA, C.U.; JESUS, R.M. Epidemiologia do traumatismo raquimedular. J Bras Neurocirurg 22 (2) 26-31, 2011.

POMPEO, D. A; ROSSI, L. A.; GALVÃO, C. M. Revisão integrativa: etapa inicial do processo de validação de diagnóstico de enfermagem. Acta paul. enferm. São Paulo, v. 22, n. 4, 2009;

REIS, J.A.P. et al. Perfil epidemiológico do traumatismo raquimedular em pacientes atendidos em um hospital da rede pública de Manaus,AM. EFDeportes.com, Revista Digital. Buenos Aires - año 18 - № 181 - Junio de 2013.

SANTIAGO, L.M.M. et al. Aspectos sociodemográficos e clínicos de homens com lesão medular traumática em um centro urbano do nordeste Brasileiro. Arquivos brasileiros de ciências da saúde, v.37, n.3, p. 137-142, Set/Dez 2012.

SANTOS, C.S.T.; GUIMARÃES, R.M.; BOEIRA, S.F. Epidemiologia do trauma raquimedular em emergências públicas no município do Rio de Janeiro. Esc Anna Nery (impr) 2012 out-dez; 16 (4):747 -753.

SANTOS, E.A.S. et al. Complicações clínicas em pacientes com trauma raquimedular cervical grave: estudo prospectivo de dez anos. Arq Neuropsiquiatr; 70(7): 524-528, 2012.

SANTOS, R.A.; ALMEIDA, M.L.O.; SILVA, M.F. Perfil clínico e epidemiológico de pacientes com traumatismo raquimedular . Fisioterapia Brasil-volume 14número 3 - maio/junho de 2013.

SCOPEL, G. et al. Avaliação do perfil epidemiológico do lesado medular traumático de um serviço de coluna do estado do Espírito Santo. Arq Bras Neurocir, Novembro 23, 2015. Rio de Janeiro, Brasil.

SILVA, G.A.; SCHOELLER, S.D.; GELBCKE, F.L.; CARVALHO, Z.M.F.; SILVA, E.M.J.P. Epidemiologia da paraplegia traumática em um centro de reabilitação em Fortaleza, Ceará, Brasil. EFDeportes.com, Revista Digital. Buenos Aires año 17, No 171 - Agosto de 2012.

TAVARES, C.B.; SOUSA, E.B.; BORGES, I.B.C.; JUNIOR, A.A.G.; NETO, N.G.F. Perfil epidemiológico dos pacientes com fratura da coluna cervical 
tratados cirurgicamente no serviço de neurocirurgia do hospital de base do Distrito Federal (Brasília, Brasil). Arq Bras Neurocirur ;35: 1-7,2016.

TAVARES, C.B.; SOUSA, E.B.; BORGES, I.B.C.; JUNIOR, A.A.G.; NETO, N.G.F.. Perfil epidemiológico dos pacientes com fraturas torácicas e lombares tratados cirurgicamente no serviço de neurocirurgia do hospital de base do Distrito Federal (Brasília, Brasil). Arq Bras Neurocirur 32(1): 19-25, 2013.

VASCONCELOS, E.C.L.M.; RIBERTO, M. Caracterização clínica e das situações de fratura da coluna vertebral no município de Ribeirão Preto, propostas para um programa de prevenção do trauma raquimedular. Coluna/columna; 10(1): 40-3, 2011.

VENTURINI, D.A.; DECÉSARO, M.N.; MARCON, S.S. Alterações e expectativas vivenciadas pelos indivíduos com lesão raquimedular e suas famílias. Rev esc enferm USP;41(4):589-96 www.ee.usp.br/reeusp/, 2007.

VIÚDES, M.A.S.; COSTA, J.M.; NUNES, C.M.P. Perfil dos pacientes internados por trauma raquimedular em hospital público de ensino. Rev Med Minas Gerais; 25(3):380-386, 2015. 